\title{
A Survey of Genetic Diversity of the Weedy Species Ipomoea lacunosa L. in the USA Mid-South
}

\author{
Nilda R. Burgos ${ }^{1}$, Daniel O. Stephenson ${ }^{2}$, Hesham A. Agrama ${ }^{3}$, Lawrence R. Oliver ${ }^{1}$, Jason A. Bond ${ }^{4}$ \\ ${ }^{1}$ Department of Crop, Soil and Environmental Sciences, University of Arkansas, Fayetteville, USA; ${ }^{2}$ Dean Lee Research Station, \\ Louisiana State University Agricultural Center, Alexandria, USA; ${ }^{3}$ Rice Research \& Extension Center, University of Arkansas and \\ Dale Bumpers National Rice Research Center, Stuttgart, USA; ${ }^{4}$ Mississippi State University, Delta Research and Extension Center, \\ Stoneville, USA. \\ Email:"nburgos@uark.edu
}

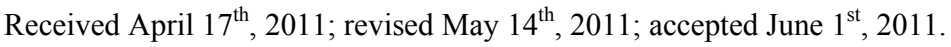

\begin{abstract}
Morningglories (Ipomoea spp.) are among the most troublesome weedy species in agroecological environments. Ipomoea lacunosa is one of the most prevalent of these species. Localized adaptations resulted in the evolution of several I. lacunosa ecotypes in North America, which could potentially impact its response to crop management practices. To evaluate the genetic diversity and population structure of I. lacunosa populations, we amplified inter-simple sequence repeats loci by polymerase chain reaction (ISSR-PCR) of 64 accessions using 14 ISSR primers for Ipomoea. Of these, 64 polymorphic fragments were scored. Analysis of Nei's genetic distance (GD) values placed the accessions into four genotypic clusters, two of which were composed primarily of accessions from Arkansas and Mississippi with GD between clusters of 0.318 . The overall GD was 0.238 , indicating a narrow genetic base. Population structure analysis determined three ancestral subgroups, with the majority of Arkansas and Mississippi accessions separated into two subgroups. The existence of various genotypes and ecotypes of I. lacunosa demonstrates the evolutionary diversification of this weedy species as it adapts to new colonized environments and agricultural activities.
\end{abstract}

Keywords: DNA Fingerprinting, Genetic Diversity, Ipomoea, ISSR, Morningglory Species, Morningglory Genotypes, Population Structure

\section{Introduction}

Plant communities in agroecosystems undergo rapid changes in composition, phenology, or genetic makeup because of exposure to strong selection factors as crop growers implement measures to favor crop growth. Examples of such activities include tillage, irrigation, fertilizer application, and use of herbicides to remove or minimize competition from weedy species. Thus, plant population composition quickly shifts to species that can thrive in these altered environments. The morningglory (Convolvulaceae) plant family is among such plant families that are well adapted to agroecosystems and are serious weeds in many crops. This family is composed of Ipomoea and Jacquemontia species, which are generally viney annuals or perennials [1]. There are more than 500 Ipomoea species worldwide [2], 342 of which exist in the Americas [3].

Annual morningglories of the genus Ipomoea are among the most troublesome weeds in numerous crops throughout the USA. Full-season interference of annual morningglories with soybean [Glycine max (L.) Merr.] causes crop lodging, reduces harvest efficiency, and reduces yield up to $75 \%$ [4]. Ipomoea lacunosa L. (pitted morningglory) is one of the more prevalent annual morningglories [5]. Its indigenous range encompasses the southern Midwest to the southeastern regions of the USA [6,7]. It is among the top 10 most troublesome weeds in southern USA row crops [8] as well as in fruit trees, nuts, and vegetable crops [9]. Full-season interference of $I$. lacunosa with soybean could cause up to $50 \%$ economic loss [10]. Morningglories have generally large seeds with hard seed coat, which contributes to its seed dormancy and persistence in the soil seed bank [1]. Being largeseeded enables it to emerge from greater depths and tolerate more stress factors around germination time than many other annual weedy species and crops; therefore, morningglories can easily become a dominant species in disturbed environments such as crop production areas. The reliance on chemical weed control in large crop 
production areas also favors the dominance of morningglories in cropping systems where the herbicides used are not effective on this weedy species [11].

The large morningglory seeds contaminate harvested crop seed or grain and allow long distance dispersal. Morphological characterization of I. lacunosa accessions in the southern USA revealed that localized morphological adaptations had occurred throughout its range, producing at least four distinct morphological ecotypes [12, 13]. Morningglories have complete flowers. Many Ipomoea species (including I. lacunosa) are self-pollinated [14], but several are insect-pollinated. The potential for hybridization between species, or populations within a species, contributes to species diversification. Plant genetic diversity emanates from accumulated genomic mutations among individuals and species with time [15] and genetic exchange between populations within a species and across genetically compatible species. Plant diversity is an inevitable consequence of interaction with other plants and the impact of environment [16] as external selectors favor the proliferation of certain individuals carrying a particular set of mutations.

Ipomoea lacunosa is widely dispersed in the southern USA. Species with wide geographic ranges, such as this, almost always develop locally adapted populations that harbor certain genetic traits allowing them to proliferate in local conditions [17]; thus, the evolution of new biotypes. Such biotypes may harbor different competitive abilities with crops, different emergence patterns, or different responses to herbicides. It is already documented that I. lacunosa accessions from southern USA have differential tolerance to sublethal (one-half the recommended) dose of glyphosate herbicide, wherein growth reduction ranged from $0 \%-40 \%$ [18]. We hypothesized that the phenotypic diversity in I. lacunosa is indicative of distinct subpopulation structure in this species. This research aimed to survey the genetic variability within $I$. lacunosa in agroecological environments in the southern USA and analyze its population structure.

\section{Materials and Methods}

\subsection{Sample Collection}

Samples were obtained from 36 locations across southern USA (Table 1, Figure 1). Seeds were primarily collected (courtesy of several colleagues) in or near agricultural fields, with each seed lot (hereafter referred to as "accessions") obtained from a single plant. Each accession was verified as I. lacunosa based on distinguishing morphological traits i.e., simple leaf margins with or without

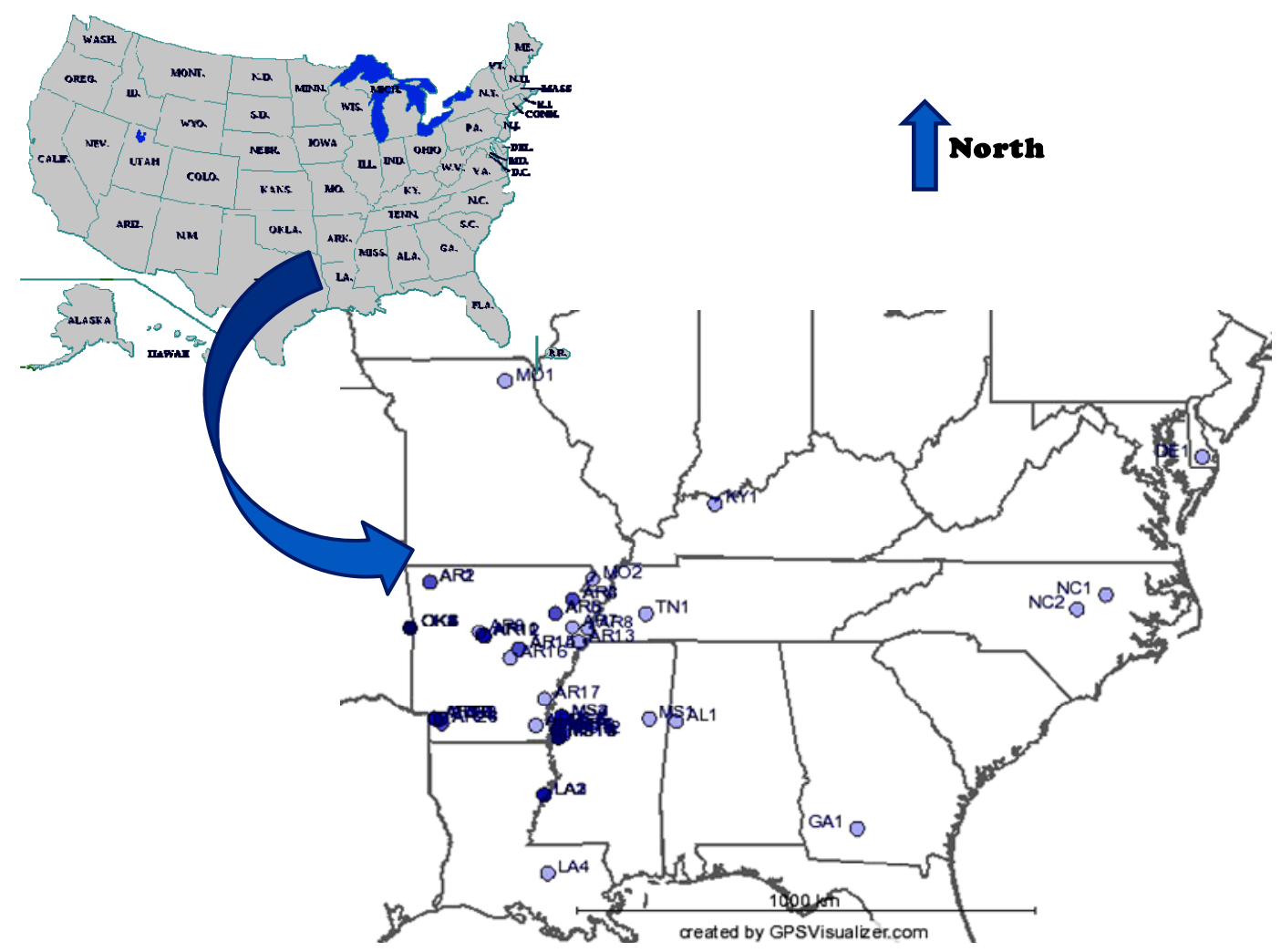

Figure 1. Geographical distribution of Ipomoea lacunosa (pitted morningglory) accessions from southern USA used in the experiment. 
Table 1. Origin of pitted morningglory (Ipomoea lacunosa L.) accessions used in the experiment and the approximate coordinates of origination sites.

\begin{tabular}{|c|c|c|c|c|c|c|}
\hline Accession & Location no. & State & Region $^{1}$ & County & $\begin{array}{l}\text { Latitude } \\
\text { EN }\end{array}$ & $\begin{array}{c}\text { Longitude } \\
\text { EW }\end{array}$ \\
\hline AL1 & 1 & Alabama & WC & Pickens & 33.42 & -88.09 \\
\hline AR1 & 2 & Arkansas & NW & Washington & 36.17 & -94.02 \\
\hline AR2 & 2 & Arkansas & NW & Washington & 36.17 & -94.02 \\
\hline AR3 & 3 & Arkansas & $\mathrm{NE}$ & Mississippi & 35.83 & -90.59 \\
\hline AR4 & 3 & Arkansas & $\mathrm{NE}$ & Mississippi & 35.83 & -90.59 \\
\hline AR5 & 4 & Arkansas & $\mathrm{NE}$ & Poinsett & 35.56 & -91.00 \\
\hline AR6 & 4 & Arkansas & $\mathrm{NE}$ & Poinsett & 35.56 & -91.00 \\
\hline AR7 & 5 & Arkansas & $\mathrm{NE}$ & Cross & 35.28 & -90.59 \\
\hline AR8 & 6 & Arkansas & $\mathrm{NE}$ & Crittenden & 35.26 & -90.22 \\
\hline AR9 & 7 & Arkansas & WC & Conway & 35.19 & -92.84 \\
\hline AR10 & 8 & Arkansas & WC & Conway & 35.12 & -92.75 \\
\hline AR11 & 9 & Arkansas & WC & Conway & 35.10 & -92.71 \\
\hline AR12 & 9 & Arkansas & WC & Conway & 35.10 & -92.71 \\
\hline AR13 & 10 & Arkansas & $\mathrm{EC}$ & St. Francis & 34.99 & -90.43 \\
\hline AR14 & 11 & Arkansas & $\mathrm{EC}$ & Lonoke & 34.85 & -91.88 \\
\hline AR15 & 11 & Arkansas & $\mathrm{EC}$ & Lonoke & 34.85 & -91.88 \\
\hline AR16 & 12 & Arkansas & $\mathrm{EC}$ & Lonoke & 34.68 & -92.09 \\
\hline AR17 & 13 & Arkansas & SE & Desha & 33.88 & -91.26 \\
\hline AR18 & 14 & Arkansas & SW & Miller & 33.48 & -93.91 \\
\hline AR19 & 15 & Arkansas & SW & Miller & 33.47 & -93.87 \\
\hline AR20 & 15 & Arkansas & SW & Miller & 33.47 & -93.87 \\
\hline AR21 & 16 & Arkansas & SW & Miller & 33.47 & -93.76 \\
\hline AR22 & 16 & Arkansas & SW & Miller & 33.47 & -93.76 \\
\hline AR23 & 17 & Arkansas & SW & Miller & 33.38 & -93.73 \\
\hline AR24 & 17 & Arkansas & SW & Miller & 33.38 & -93.73 \\
\hline AR25 & 18 & Arkansas & SE & Ashley & 33.34 & -91.47 \\
\hline DE1 & 19 & Delaware & $\mathrm{SC}$ & Sussex & 38.66 & -75.42 \\
\hline GA1 & 20 & Georgia & $\mathrm{SC}$ & Colquitt & 31.30 & -83.73 \\
\hline KY1 & 21 & Kentucky & NW & Daviess & 37.72 & -87.16 \\
\hline LA1 & 22 & Louisiana & $\mathrm{NE}$ & Tensas & 31.96 & -91.27 \\
\hline LA2 & 22 & Louisiana & $\mathrm{NE}$ & Tensas & 31.96 & -91.27 \\
\hline LA3 & 22 & Louisiana & $\mathrm{NE}$ & Tensas & 31.96 & -91.27 \\
\hline LA4 & 23 & Louisiana & SE & West Baton Rouge & 30.41 & -91.18 \\
\hline MO1 & 24 & Missouri & $\mathrm{NE}$ & Knox & 40.16 & -92.21 \\
\hline MO2 & 25 & Missouri & SE & Dunklin & 36.23 & -90.10 \\
\hline
\end{tabular}




\begin{tabular}{|c|c|c|c|c|c|c|}
\hline Accession & Location no. & State & Region $^{1}$ & County & $\begin{array}{l}\text { Latitude } \\
\text { EN }\end{array}$ & $\begin{array}{c}\text { Longitude } \\
\text { EW }\end{array}$ \\
\hline MS1 & 26 & Mississippi & $\mathrm{EC}$ & Noxubee & 33.47 & -88.74 \\
\hline MS2 & 27 & Mississippi & WC & Washington & 33.52 & -90.85 \\
\hline MS3 & 27 & Mississippi & WC & Washington & 33.52 & -90.85 \\
\hline MS4 & 27 & Mississippi & WC & Washington & 33.52 & -90.85 \\
\hline MS5 & 28 & Mississippi & WC & Washington & 33.33 & -90.91 \\
\hline MS6 & 28 & Mississippi & WC & Washington & 33.33 & -90.91 \\
\hline MS7 & 28 & Mississippi & WC & Washington & 33.33 & -90.91 \\
\hline MS8 & 28 & Mississippi & WC & Washington & 33.33 & -90.91 \\
\hline MS9 & 29 & Mississippi & WC & Washington & 33.24 & -90.78 \\
\hline MS10 & 30 & Mississippi & WC & Washington & 33.24 & -90.97 \\
\hline MS11 & 31 & Mississippi & WC & Washington & 33.21 & -90.91 \\
\hline MS12 & 32 & Mississippi & WC & Washington & 33.16 & -90.82 \\
\hline MS13 & 32 & Mississippi & $\mathrm{WC}$ & Washington & 33.10 & -90.92 \\
\hline MS14 & 32 & Mississippi & WC & Washington & 33.10 & -90.92 \\
\hline MS15 & 32 & Mississippi & $\mathrm{WC}$ & Washington & 33.10 & -90.92 \\
\hline MS16 & 32 & Mississippi & WC & Washington & 33.10 & -90.92 \\
\hline MS17 & 32 & Mississippi & WC & Washington & 33.10 & -90.92 \\
\hline $\mathrm{NC} 1$ & 33 & North Carolina & $\mathrm{NE}$ & Edgecombe & 35.92 & -77.74 \\
\hline $\mathrm{NC} 2$ & 34 & North Carolina & $\mathrm{C}$ & Johnston & 35.64 & -78.44 \\
\hline OK1 & 35 & Oklahoma & EC & Sequoyah & 35.27 & -94.50 \\
\hline OK2 & 35 & Oklahoma & $\mathrm{EC}$ & Sequoyah & 35.27 & -94.50 \\
\hline OK3 & 35 & Oklahoma & $\mathrm{EC}$ & Sequoyah & 35.27 & -94.50 \\
\hline OK4 & 35 & Oklahoma & $\mathrm{EC}$ & Sequoyah & 35.27 & -94.50 \\
\hline OK5 & 35 & Oklahoma & $\mathrm{EC}$ & Sequoyah & 35.27 & -94.50 \\
\hline OK6 & 35 & Oklahoma & $\mathrm{EC}$ & Sequoyah & 35.27 & -94.50 \\
\hline OK7 & 35 & Oklahoma & $\mathrm{EC}$ & Sequoyah & 35.27 & -94.50 \\
\hline OK8 & 35 & Oklahoma & $\mathrm{EC}$ & Sequoyah & 35.27 & -94.50 \\
\hline OK9 & 35 & Oklahoma & $\mathrm{EC}$ & Sequoyah & 35.27 & -94.50 \\
\hline TN1 & 36 & Tennessee & WC & Madison & 35.55 & -88.82 \\
\hline
\end{tabular}

${ }^{1}$ Abbreviations: C, central; EC, east-central; NE, northeast; NW, northwest; SE, southeast; SW, southwest; WC, west-central.

Sharp points on the sides, relatively glabrous on both leaf surfaces, while flowers. The study included 64 singleplant accessions from 33 collection sites in 10 states of the southern USA. The majority of accessions were collected from the mid-south specifically, Arkansas and Mississippi. Seed from the original, single-plant accessions were planted and characterized in a common garden at the University of Arkansas Agricultural Research Center, Fayetteville [12]. Young leaf tissues were col- lected from plants grown in a common garden and used for DNA fingerprinting.

\subsection{DNA Extraction}

Approximately $5 \mathrm{~cm}^{2}$ of young leaf tissues were harvested per plant, with three biological replicates per accession. Tissues were stored in microcentrifuge tubes at $-80^{\circ} \mathrm{C}$ until processed. DNA was extracted using a hexadecyltrimethylammonium bromide $(\mathrm{CTAB})$ method 
[19] with some modifications. Frozen leaf tissue was placed in liquid $\mathrm{N}_{2}$ for $30 \mathrm{~s}$, ground with a mortar and pestle, and transferred to a chilled $1.5-\mathrm{ml}$ microcentrifuge tube. Extraction buffer (100 mM Tris-HCl, pH 8.0; $20 \mathrm{mM}$ EDTA, pH 8.0; $1 \mathrm{M} \mathrm{NaCl} ; 2 \%$ CTAB; $2 \%$ polyvinylpyrrlidone-40; $1 \mathrm{mM}$ phenanthroline; $0.2 \% \beta$-mercaptoethanol), $500 \mu \mathrm{l}$, was added; the samples were vortexed (Vortex-Genie2, Scientific Industries Inc., 70 Orville Dr., Bohemia, NY 11716 , USA) briefly and incubated at $65^{\circ} \mathrm{C}$ for 45 min, occasionally inverting the tubes to mix the sample. The ground tissue was extracted with $500 \mu$ l of phenol:chloroform:isoamylalcohol $(25: 25: 1)$ and centrifuged at $10,000 \mathrm{rpm}$ at $4^{\circ} \mathrm{C}$ for $10 \mathrm{~min}$. The aqueous fraction was recovered, $500 \mu 1$ of isopropanol was added, mixed gently by inverting the tubes, and centrifuged at 12,000 rpm at $4^{\circ} \mathrm{C}$ for $10 \mathrm{~min}$. The DNA pellet was washed with $500 \mu 100 \% \mathrm{EtOH}$, dried in a vacufuge, and redissolved in $50 \mu \mathrm{l}$ of TE buffer $(10 \mathrm{mM}$ Tris- $\mathrm{HCl}, \mathrm{pH} 8.0$, with 1 mM EDTA). The DNA concentration was quantified with a fluorometer (DyNA Quant 200, Amersham Pharmacia Biotech AB, 654 Minnesota St., San Francisco, CA 94107, USA) using calf thymus DNA (Sigma-Aldrich, 3050 Spruce St., St. Louis, MO 63103, USA) as standard. DNA concentrations were then adjusted to 20 $\mathrm{ng} \cdot \mu \mathrm{l}^{-1}$ with deionized water for subsequent amplification reactions using the ISSR (inter-simple sequence repeats) primers.

\subsection{PCR-Amplification of ISSR Loci}

Primers designed to amplify ISSR in the cultivated relative Ipomoea batatas L. (sweet potato) were used [20]. Simple sequence repeats are tandemly repeated, noncoding short segments of genomic DNA [21,22]. These repetitive segments are ubiquitous, hypervariable, and widely distributed in the genome [15,23,24]. For SSRDNA fingerprinting, primers are designed for regions flanking the repetitive segment; therefore, sequence information of the flanking region is required [15,25]. To circumvent this hurdle, Zietkiewicz et al. developed the alternative ISSR approach [22], which has been successfully used in various species $[23,26-28]$. These primers are degenerate and are designed to anneal to the repetitive segments. This approach revealed sufficient variation within the Ipomoea genus to allow for analysis of intraspecific diversity [20].

The reaction mixture consisted of $1 \mu$ DNA template plus reagents in the PCR kit (HotStarTaq PCR Handbook, Qiagen Inc., 28159 Avenue Stanford, Valencia, CA 91355, USA). The PCR reagents included $2 \mu 1$ 10X PCR buffer; $4 \mu 1$ XX Q-solution, $0.5 \mu l$ (2.5 units) HotStar Taq polymerase, $25 \mathrm{mM} \mathrm{MgCl} 2,5 \mu \mathrm{l}(10 \mathrm{mM})$ dNTPs (Promega Corporation, 2800 Woods Hollow Road, Madison, WI 53711, USA), $6.5 \mu \mathrm{l}$ deionized water, and $1 \mu \mathrm{l}$ (10 pmol) ISSR primer in a final volume of $20 \mu$ l. Fifteen ISSR primers (Sigma Genosys, 1442 Lake Front Circle, The Woodlands, TX 77380, USA) were used (Table 2). Reactions without DNA were included in each batch of PCRs as negative control. Duplicate reactions were prepared for all samples to monitor repeatability.

Amplification reactions were performed with a PTC200 Peltier Thermal Cycler (MJ Research Inc., 149 Grove St., Watertown, MA 02472, USA). After 15-min incubation at $94^{\circ} \mathrm{C}$, the PCR mixtures were subjected to 45 cycles of $94^{\circ} \mathrm{C}$ for $45 \mathrm{~s}, 50^{\circ} \mathrm{C}-55^{\circ} \mathrm{C}$ (depending on the primer used) for $45 \mathrm{~s}, 72^{\circ} \mathrm{C}$ for $1.5 \mathrm{~min}$, and a final 7 min extension at $72^{\circ} \mathrm{C}$. The reaction tubes were then held at $4^{\circ} \mathrm{C}$ until analyzed. The amplified fragments were resolved in $1.6 \%$ agarose gels (containing 3\% ethidium bromide) in $0.5 \mathrm{X}$ TBE buffer ( $45 \mathrm{mM}$ Tris-borate, $1 \mathrm{mM}$ EDTA), run at $250 \mathrm{v}$ for $45 \mathrm{~min}$ and visualized using a UV transilluminator (Electronic Dual Light-Transilluminator, Ultra-Lum Inc., 1480 North Claremont Blvd., Claremont, CA 91711, USA). Reproducible amplified DNA fragments were scored as binary data whether present (1) or absent (0).

\subsection{Analysis of Genetic Diversity and Population Structure}

The binary matrix of ISSR marker scores was analyzed to generate a matrix of genetic distance (GD) and similarity coefficients according to the procedure of Nei [29] using the PowerMarker v3.25 software [30]. The software NTSYS-pc 2.21 [31] was used to construct a dendogram using an Unweighted Pair Group Method with Algorithmic Mean (UPGMA) based on Nei's similarity coefficients. NTSYS-pc 2.21 was also used to compute Principal Component Analysis (PCA) for the 64 genotypes using the marker data. Principal component analysis (PCA) is widely used technique for dimensional reduction and data summary. It enables the identification of key components of the structure within the data without resorting to a model [32]. Because the markers used to estimate the panel structures are chosen so as to be physically distant and selectively neutral, the linkage disequilibrium between them is due principally to the panel stratification, the panel structure is thus the main information that is summarized by the first components.

A Bayesian clustering procedure in the STRUCTURE software $[33,34]$ was used to determine the population structure using multi-locus genotype data to identify groups being characterized by specific sets of marker allele frequencies. Bayesian methods [33] and PCA [35, 36] are widely used to elucidate genetic diversity and population structure of cultivated, wild, and weedy relatives of rice [37-43]. The Bayesian model-based clustering method assumes Hardy-Weinberg and linkage equi- 
librium between the loci within the subpopulations. Starting with uniform priors, information about the origins of the individuals (in the case of mixture) or about the origin of proportions of individual genomes (in the case of admixture) is inferred. Approximations of posterior distributions are obtained using Markov chain Monte Carlo (MCMC) methods.

This model-based procedure probabilistically assigns accessions to an assumed number $(\mathrm{K})$ of different subgroups aiming to minimize LD (linkage disequilibrium) and maximize gametic-phase equilibrium within populations. $\mathrm{K}$ indicates the ancestries or populations discernable among the samples analyzed. The program was run for $\mathrm{K}$ ranging from 2 to 12 with 20 independent replications per K. For this we used the admixture model with uncorrelated allele frequencies setting a burn-in length of 20,000 iterations followed by 50,000 MCMC iterations. For each value of $\mathrm{K}$, STRUCTURE produces a Q-matrix (QST) that lists the estimated membership coefficients for each accession in each subgroup. An individual having more than $70 \%$ of its genome fraction value under a particular K subgroup was assigned to that subgroup. The model choice criterion implemented in STRUCTURE, i.e. $\mathrm{LnP}(\mathrm{D})$, which is the estimate for the posterior probabi- lity of the data for a given $\mathrm{K}$, frequently did not show a clear trend (Figure 2(a)). To identify the most likely number $\mathrm{K}$ of subgroups, we additionally used the approaches of Evanno et al. [44]. Evanno et al. [44] suggested an ad hoc statistic $\Delta \mathrm{K}$ determining the break in the slope of the LnP(D) probability function (Figure 2(b)) provided by STRUCTURE. Analysis of molecular variance (AMOVA) was also conducted using Arlequin 3.11 software [45] to partition the contribution of within and among population variation to the formation of subpopulations. Accessions were considered admix if their genomic values indicated shared alleles between two or more subpopulations.

\section{Results}

\subsection{Polymorphism of I. Lacunosa ISSR Loci}

Fourteen of the $15 \mathrm{I}$. batatas ISSR primers amplified several hypervariable loci in I. lacunosa. The bands scored ranged from $250 \mathrm{bp}$ to $1500 \mathrm{bp}$ in size. A total of 67 DNA fragments were amplified across all accessions, 64 of which were polymorphic (Table 2). Each primer amplified 2 to 9 DNA fragments, with an average of 4.5 bands per primer. The 14 primers all together amplified 16 to 37 fragments per accession.

Table 2. DNA sequences of the primers used for ISSR-PCR, annealing temperatures, and the number of polymorphic bands scored across all samples.

\begin{tabular}{|c|c|c|c|c|}
\hline Primer & Sequence $\left(5^{\prime} \text { to } 3^{\prime}\right)^{\mathrm{a}}$ & Annealing temperature $\left({ }^{\circ} \mathrm{C}\right)$ & Total bands scored & Polymorphic bands \\
\hline ISSR-1 & AGAGAGAGAGAGAGAGT & 50.5 & 4 & 4 \\
\hline ISSR-2 & GAGAGAGAGAGAGAGAC & 53.0 & 2 & 2 \\
\hline ISSR-3 & CACACACACACACACAA & 51.5 & 5 & 4 \\
\hline ISSR-4 & GTGTGTGTGTGTGTGTA & 52.5 & 4 & 4 \\
\hline ISSR-5 & ACACACACACACACACT & 52.5 & 3 & 3 \\
\hline ISSR-6 & AGAGAGAGAGAGAGAGYC & 53.5 & 3 & 2 \\
\hline ISSR-7 & GAGAGAGAGAGAGAGAYC & 51.5 & 6 & 6 \\
\hline ISSR-8 & GTGTGTGTGTGTGTGTYC & 55.0 & 4 & 4 \\
\hline ISSR-9 & ACACACACACACACACYG & 55.0 & 5 & 5 \\
\hline ISSR-10 & ACCACCACCACCACCACC & 51.5 & 8 & 8 \\
\hline ISSR-11 & ATGATGATGATGATGATG & 52.0 & 4 & 3 \\
\hline ISSR-12 & GGATGGATGGATGGAT & 50.5 & 5 & 5 \\
\hline ISSR-13 & BDBCACACACACACACA & 52.0 & 0 & 0 \\
\hline ISSR-14 & VHVGTGTGTGTGTGTGT & 50.0 & 9 & 9 \\
\hline ISSR-15 & HVHTGTGTGTGTGTGTG & 51.5 & 6 & 6 \\
\hline Total & & & 67 & 64 \\
\hline
\end{tabular}

${ }^{\mathrm{a}} \mathrm{Y}=$ pyrimidine; $\mathrm{B}=\mathrm{C}, \mathrm{G}$, or $\mathrm{T} ; \mathrm{D}=\mathrm{A}, \mathrm{G}$, or $\mathrm{T} ; \mathrm{H}=\mathrm{A}, \mathrm{C}$, or $\mathrm{T}$; and $\mathrm{V}=\mathrm{A}, \mathrm{C}$, or $\mathrm{G}$. 


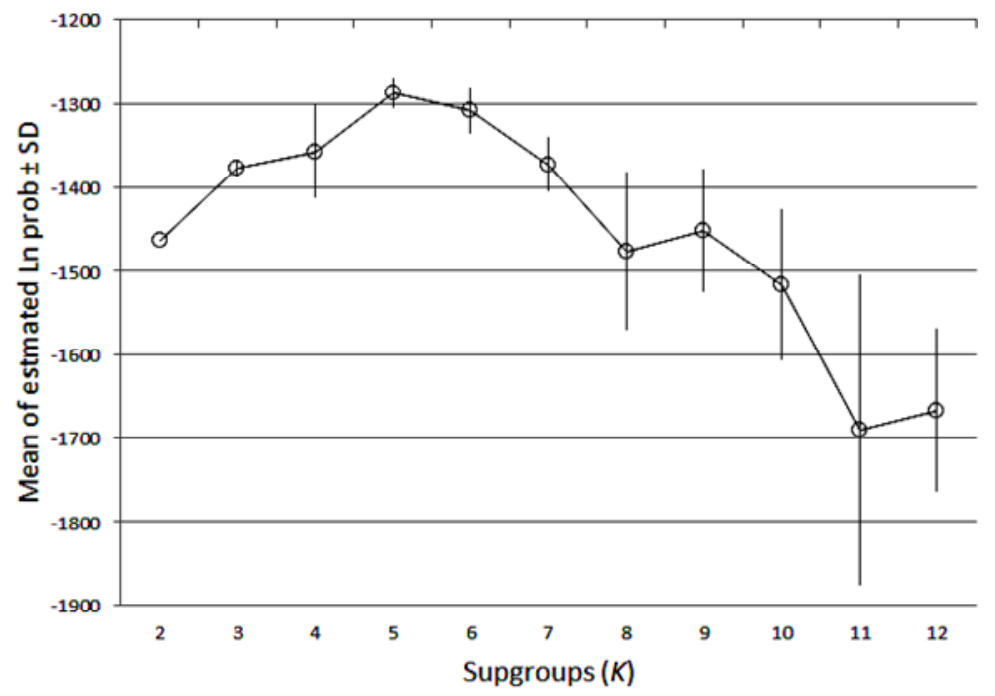

(a)

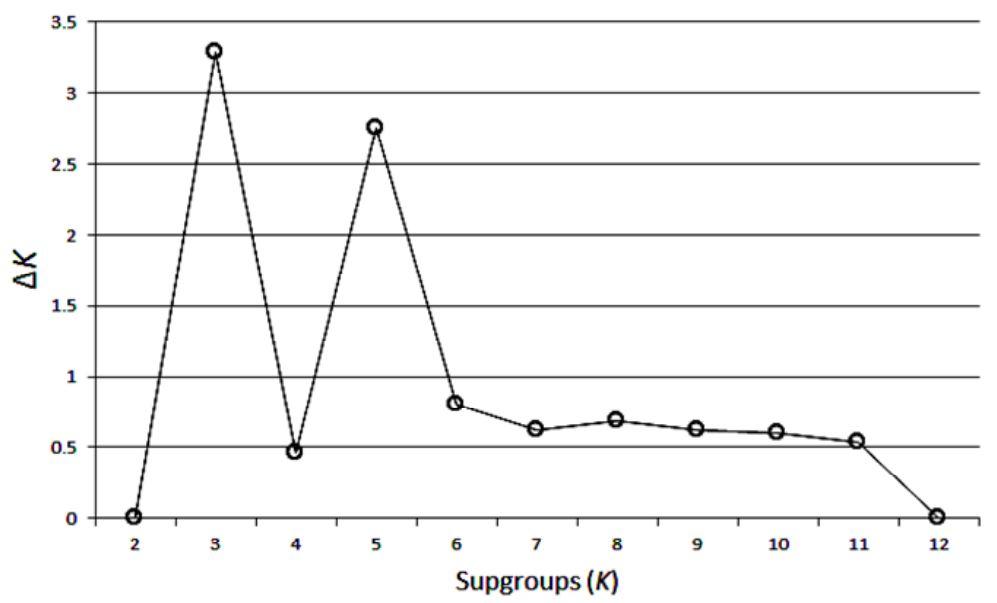

(b)

Figure 2. Analysis of optimum ancestral subgroups for Ipomoea lacunosa (pitted morningglory) accessions, mostly from the southern USA using STRUCTURE software.

\subsection{Genetic Diversity of I. Lacunosa from Southern USA}

In this study, Arkansas (AR) and Mississippi (MS) were more intensively sampled than the other states at 25 and 17, respectively. The overall GD among AR accessions was 0.206 and that of the MS accessions was 0.201 . The 64 accessions separated into four genotypic clusters (Figure 3) with an overall average GD of 0.238. This is relatively low, similar to that of rice cultivars grown in the USA with an overall GD of 0.26 , indicating a narrow genetic base [41]. The largest cluster (cluster 1) was composed of 38 accessions with three subclusters. The majority (83\%) of accessions from AR fell in subcluster 1a. The one accession each from Alabama (AL1), Delaware (DE1) and Kentucky (KY1), two accessions from North Carolina (NC), and one accession from Mississippi
(MS3) also were in the large AR subcluster. Another accession from MS (MS1) grouped with three AR accessions in subcluster 1c. The remaining 15 (88\%) MS accessions fell in cluster 4, where one AR accession (AR10) also belonged. Thus, in general, AR and MS accessions belonged to different genotypic groups with an average GD of 0.318 between groups. All nine accessions from East-central Oklahoma (OK), which were collected from one field, composed subcluster $1 \mathrm{~b}$. The average GD within the $\mathrm{OK}$ population was 0.146 , indicating that plants in this field were very highly similar. Genetic similarity approaches 1.0 as GD approaches 0 . Although the OK accessions were collected from a field close to the AR border, collectively the OK population belonged to a different genotypic subgroup relative to the AR population with an average GD of 0.269 among the two populations. The two accessions from eastern Missouri 
(MO) grouped with AR1 and AR5 from northern AR in cluster 2. One accession from Tennessee (TN1) was in a cluster by itself (cluster 3). The four Louisiana (LA) accessions were all in cluster 4 , together with the majority of MS accessions. The one accession from Georgia (GA1) also fell in the large MS cluster, forming a subcluster with three of the LA accessions.

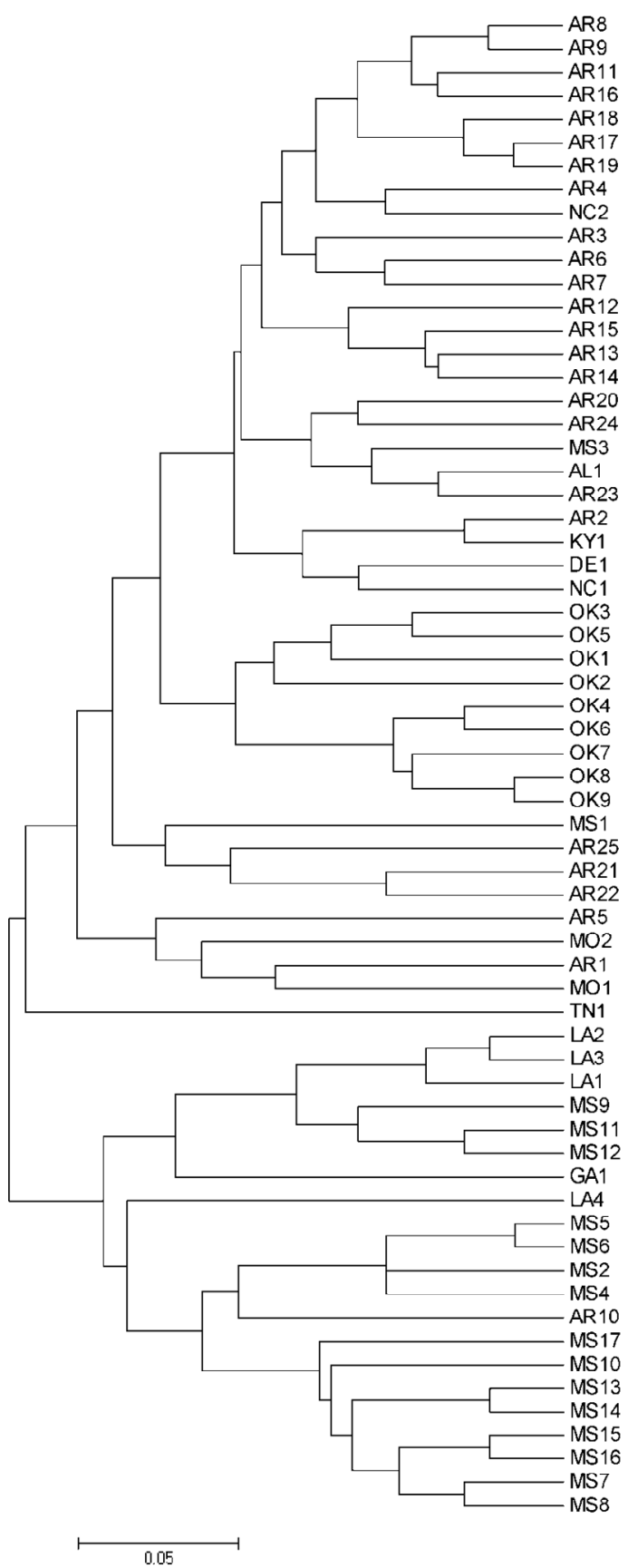

Figure 3. UPGMA tree of 64 accessions of Ipomoea lacunosa (pitted morningglory) mostly from the southern USA, based on Nei's [29] similarity coefficients using NTSYS-pc 2.21 software.
The LA accessions and GA1 originated from latitudes of $31.97^{\circ} \mathrm{N}$ or further south (Table 1). In many cases in this data set, accessions collected along the same latitude were more genetically similar. The grouping of LA accessions and GA1 within the same genotypic subcluster indicates that longitude (within its habitat range) might not influence genetic variation of I. lacunosa as much as latitude would. The LA and AR accessions were from a longitude of $-91.18^{\circ} \mathrm{W}$ to $-91.27^{\circ} \mathrm{W}$, while GA1 was from a longitude of $-83.73^{\circ} \mathrm{W}$. However, to properly define the relationship between latitude and species diversification of I. lacunosa, a follow-up experiment need to be conducted involving intensive and structured sampling along different latitudinal gradients. Different ecotypes of this species [12] may also be dispersed along latitudinal gradient depending on its photoperiodicity [46].

\subsection{Population Structure of I. Lacunosa}

The most probable number of ancestral lineage $(\mathrm{K})$ of these accessions is three (Figure 2(a)). This is the number of subgrouping that optimizes $\Delta \mathrm{K}$ (Figure 2(b)). The partitioning of molecular variance within and among subpopulations was significant $(P<0.0001)$ and the greatest contribution to population genetic divergence (73\%) emanated from within the subpopulation (Figure 4). The majority (15 of 25) AR accessions, which constituted a large proportion of genotypic cluster 1, fell under subpopulation K1 (Figure 5). This subpopulation also included the two accessions from $\mathrm{MO}$, the two accessions from $\mathrm{NC}$, and the single accessions from $\mathrm{DE}$, $\mathrm{KY}$, and TN. Only the MS1 accession from MS belonged to this group. Three accessions in this group were admixtures (AR14, AR12, AR4), sharing $>30 \%$ of its alleles with other subgroups (Table 3).

The second subpopulation (K2) included all accessions from $\mathrm{OK}$, seven accessions from $\mathrm{AR}$, and the one accession from Alabama (AL1) (Figure 5). Specifically, this included subclusters $1 \mathrm{~b}$ and $1 \mathrm{c}, 32 \%$ of accessions from subcluster 1a, and two (AR4 and NC2) of four accessions from cluster 2 (Figure 3). Three accessions in this subgroup were admixtures: OK2, AR16, and AL1 (Table 3).

The third subpopulation (K3) included all accessions from MS (except MS1) and LA, two accessions from AR (AR10, AR23), and the single accession from GA (Figure 5). Thus, this ancestral subgroup covered all accessions in genotypic cluster 4 (Figure 3). Five accessions in this subpopulation were admixtures (Table 3 ), generally sharing alleles with $\mathrm{K} 1$. The presence of admix accessions indicated genetic introgression between subpopulations.

\section{Discussion}

ISSR markers have been used to study the genetic diversity of crops including barley [47], rice [48], sweet potato [20], 
and wheat [49]. These markers are highly polymorphic and can be used to study intraspecific population structure. The polymorphism of ISSR markers in I. lacunosa was high (95\%), which makes this PCR-based approach a good tool for studying the population genetics and evolution of the Ipomoea species complex when coupled with some gene sequence information. In a study of 10 cultivated and weedy Ipomoea species using ISSR markers, the highest level of ISSR polymorphism was observed in the weedy species $I$. trifida at 78.1\% [20]. Among various Ipomoea species, intraspecific accessions almost always clustered together [20]. In the present study involving one Ipomoea species, we provided further evidence of the sensitivity of ISSRs in detecting subpopulation differentiations in that, accessions from proximal localities (i.e. AR or MS accessions) generally clustered together. Further, accessions from one field (i.e. OK accessions) also clustered together.

The clustering of LA accessions with those of MS or the eastern MO accessions with northern AR accessions was not surprising because of the geographical proximity of the collection sites in these states and the high similarity of their agricultural environments. The clustering of the one GA accession with MS and LA accessions indicated shared ancestry, which could be due to colonization of new areas via seed movement. The large morningglory seeds make it easy for the weed seed to be harvested, and moved, with the crop. Interstate transport of crop grains is a common means of spreading weed seeds. The same principle applies to the clustering of $\mathrm{AL}, \mathrm{DE}, \mathrm{KY}$, and $\mathrm{NC}$ accessions with AR accessions. It is also possible that the colonization of I. lacunosa in the southern USA started with only one genotype and evolved with time due to localized adaptations and hybridization with compatible species [13]. This premise is supported by STRUCTURE analysis, which determined three subpopulations of I. lacunosa where the majority of AR accessions shared the same ancestry (K1) and all but one MS accessions also shared the same ancestry (K3). Some AR accessions shared the same ancestry as the $\mathrm{OK}$ accessions (K2) apparently due to short-distance dispersal; on the other hand, accessions from distant states belonged to the AR or MS subpopulation. This indicates that seeds have been moved to distant locations at some point in the past and thereafter had colonized new geographies. The direction of movement could not be resolved in this study. To determine if the evolution of localized subpopulations commonly occurs in other geographies and microclimates, a follow-up study needs to be conducted with intensive sampling in various geographic locales.

The presence of admix genotypes indicates genetic introgression between subpopulations, which could be due

\section{Partitioning of Molecular Variance}

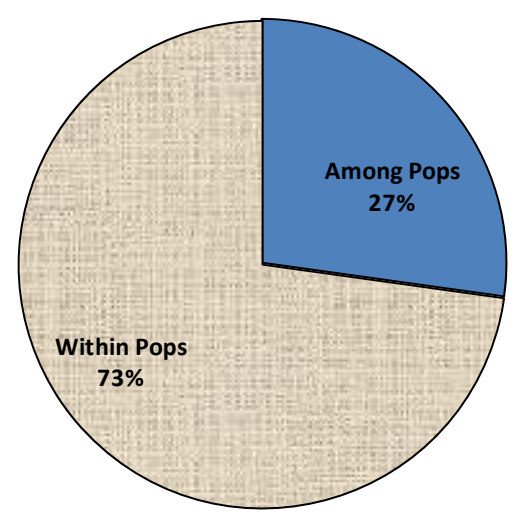

Figure 4. Partitioning of molecular variance among Ipomoea lacunosa (pitted morningglory) accessions from the southern USA Analysis of molecular variance (AMOVA) using Arlequin 3.11 software.

Table 3. Shared ancestry among some Ipomoea lacunosa accessions from the southern USA.

\begin{tabular}{|c|c|c|c|c|c|}
\hline \multirow[t]{2}{*}{ Sample code } & \multirow[t]{2}{*}{ Sampling location } & \multirow[t]{2}{*}{$\mathrm{K}$ group assignment } & \multicolumn{3}{|c|}{ Allele sharing (proportion) ${ }^{\mathrm{a}}$} \\
\hline & & & $\mathrm{K} 1$ & $\mathrm{~K} 2$ & K3 \\
\hline AR14 & East-central Arkansas & 1 & 0.566 & 0.422 & 0.011 \\
\hline AR12 & West-central Arkansas & 1 & 0.696 & 0.287 & 0.017 \\
\hline AR4 & Northeast Arkansas & 1 & 0.423 & 0.267 & 0.310 \\
\hline $\mathrm{OK} 2$ & East-central Oklahoma & 2 & 0.380 & 0.606 & 0.014 \\
\hline AR16 & East-central Arkansas & 2 & 0.295 & 0.683 & 0.022 \\
\hline AL1 & West-central Alabama & 2 & 0.335 & 0.389 & 0.275 \\
\hline LA3 & Northeast Louisiana & 3 & 0.324 & 0.037 & 0.639 \\
\hline AR10 & West-central Arkansas & 3 & 0.432 & 0.127 & 0.441 \\
\hline MS3 & West-central Mississippi & 3 & 0.429 & 0.051 & 0.520 \\
\hline LA4 & South Louisiana & 3 & 0.396 & 0.009 & 0.595 \\
\hline AR23 & Southwest Arkansas & 3 & 0.083 & 0.328 & 0.590 \\
\hline
\end{tabular}

${ }^{\mathrm{a}} \mathrm{An}$ individual having $>70 \%$ of its genome fraction value fall within a particular $\mathrm{K}$ subpopulation was assigned to that group. Otherwise, if a substantial proportion of alleles are shared between subpopulations, such individual is considered an admixture of different ancestries. 


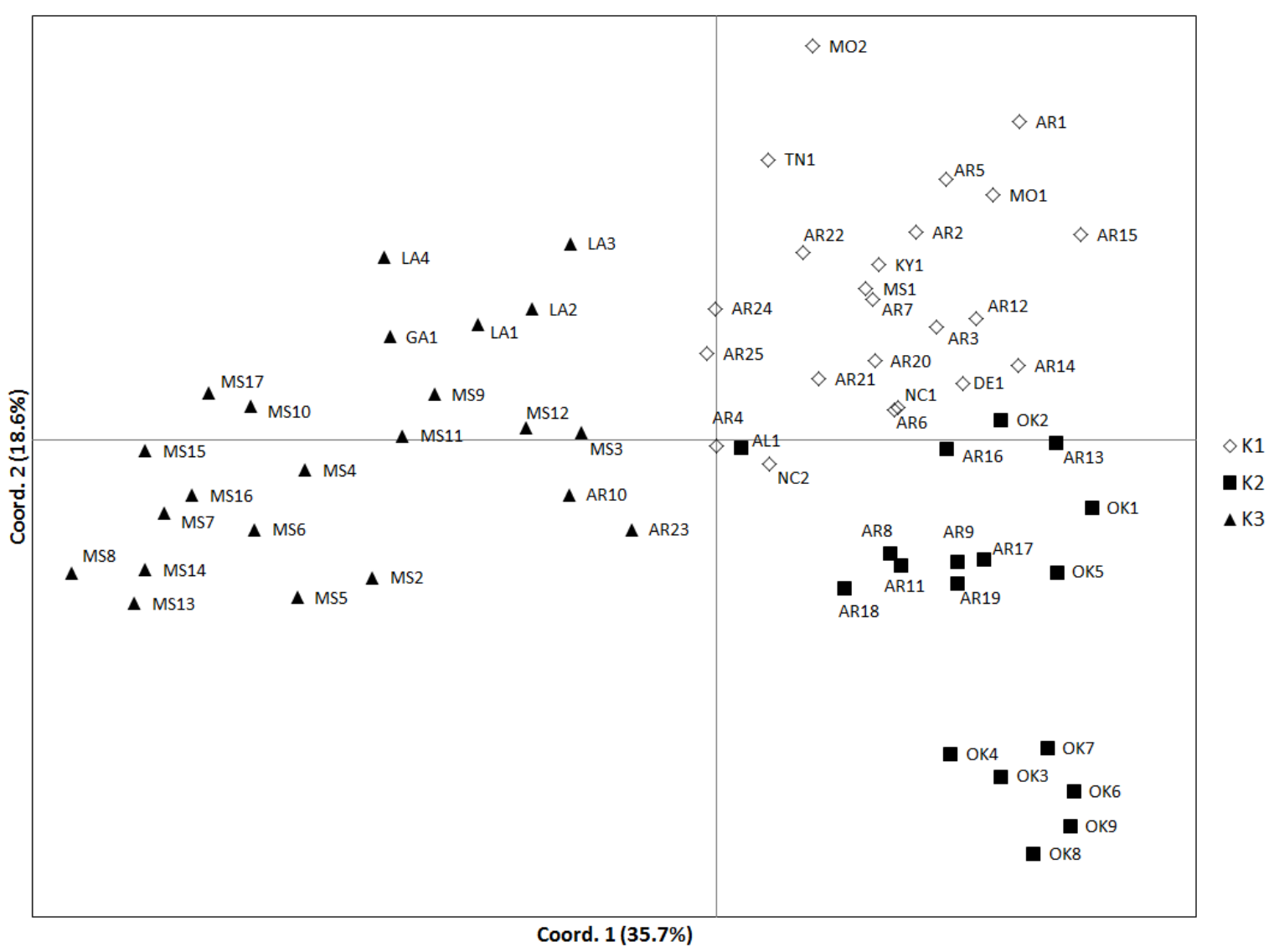

Figure 5. Principal component analysis (PCA) of ISSR markers using STRUCTURE software, showing the separation of Ipomoea lacunosa (pitted morningglory) accessions into three subpopulations. Numbers in parenthesis are the proportions of genomic variation explained by the component.

to recent gene flow or shared alleles from the distant past. The data set could not distinguish between these factors. Similarly, admix genotypes of weedy rice had been detected, which was principally attributed to natural hybridization between weedy rice types [41]. The same interaction could occur in I. lacunosa. Although there is no data on the extent of cross pollination in this species, pollination by insects is most likely, and hybrid Ipomoea had been observed [13].

Just as four morphological ecotypes of I. lacunosa have been identified [12], three genetic subpopulations have been determined in the present study, using the same accessions previously used in the morphological diversity characterization. These demonstrate the morphological and genetic divergence of I. lacunosa in southern USA, which impacts the efficacy of weed management strategies. For example, Burke et al. [18] showed significant variation in tolerance of I. lacunosa accessions to sublethal dose of glyphosate herbicide. Glyphosate is a non-selective herbicide used as the main tool to kill weeds in glyphosateresistant crops. The doses of glyphosate that would reduce the growth of $I$. lacunosa accessions by $50 \%\left(\mathrm{GR}_{50}\right)$ ranged from $0.65 \mathrm{~kg} \cdot \mathrm{ha}^{-1}$ to $1.23 \mathrm{~kg} \cdot \mathrm{ha}^{-1}$ [18]. Farmers find it difficult to control this weed. Genetic and morphological diversity could also result in different emergence behaviors between genotypes. This would allow I. lacunosa to escape weed management tactics that are usually implemented early in the crop growing season.

\section{Conclusions}

The overall genetic diversity of I. lacunosa from the southern USA is low, which is indicative of a predominantly selfing mating behavior or a narrow ancestral genetic base. The species has diverged into different genotypic clusters and subpopulations in the mid-south. The subpopulations were generally geographically delimited, indicating the evolution of locally adapted weedy populations. Differential tolerance of I. lacunosa to herbicides, as reported by other researchers, maybe correlated with genetic subpopulation differentiation in this species.

\section{Acknowledgements}

We thank Drs. Shawn Askew, Jeffery W. Barnes, Jeffery 
W. Edwards, James L. Griffin, Robert Hayes, William G. Johnson, Donnie K. Miller, Edward C. Murdock, Don S. Murray, Eric Palmer, Andrew Price, Jason C. Sanders, Mark Van Gessel, William Vencill, Blaine J. Viator, and the late Drs. William Barrentine and John W. Wilcut for contributing seed samples for this research. We also thank Dr. Satyendra N. Rajguru, former Postdoctoral Associate, for his help in setting up the DNA fingerprinting process. They made this research possible.

\section{REFERENCES}

[1] C. D. Elmore, H. R. Hurst and D. F. Austin, "Biology and Control of Morningglories (Ipomoea spp.)," Reviews in Weed Science, Vol. 5, 1990, pp. 83-114.

[2] J. A. McDonald and T. J. Mabry, "Phylogenetic Systematic of New World Ipomoea (Convolvulaceae) Based on Chloroplast DNA Restriction Site Variation," Plant Systematic Evolution, Vol. 180, 1992, pp. 243-259.

[3] D. F. Austin and Z. Huáman, "A Synopsis of the Ipomoea (Convolvulaceae) in the Americas," Taxon, Vol. 45, 1996, pp. 3-38.

[4] M. A. Barker, L. Thompson Jr and F. M. Godley, "Control of Annual Morningglories (Ipomoea spp.) in Soybeans (Glycine max)," Weed Science, Vol. 32, 1984, pp. 813-818.

[5] C. D. Elmore, J. B. Wiseman and S. McDaniel, "Morningglory Survey of Cotton and Soybean Fields in the Mississippi Delta: 1981," Proceedings of Southern Weed Science Society, Vol. 35, 1982, pp. 319-328.

[6] M. L. Fernald, "Gray's Manual of Botany," 8th Edition (Centennial), American Book Company, New York, 1950.

[7] A. E. Radford, H. E. Ahles and C. R. Bell, "Manual of the Vascular Flora of the Carolinas," The University of North Carolina Press, Chapel Hill, 1968.

[8] T. M. Webster, "Weed Survey-Southern States: Broadleaf Crops Subsection," Annual Meeting Abstracts, Southern Weed Science Society, Champaign, 2005.

[9] T. M. Webster, "Weed Survey—Southern States: Vegetables, Fruits and Nut Crops," Annual Meeting Abstracts, Southern Weed Science Society, Champaign, 2006.

[10] O. W. Howe III and L. R. Oliver, "Influence of Soybean (Glycine max) Row Spacing on Pitted Morningglory Interference," Weed Science, Vol. 35, 1987, pp. 185-193.

[11] C. D. Elmore, "Weed Survey-Southern States," Southern Weed Science Society Report, Vol. 37, 1984, pp. 192-198.

[12] D. O. Stephenson IV, L. R. Oliver, N. R. Burgos and E. E. Gbur Jr, "Identification and Characterization of Pitted Morningglory (Ipomoea lacunosa) Ecotypes," Weed Science, Vol. 54, No. 1, 2006, pp. 78-86. doi:10.1614/WS-04-205R.1

[13] C. T. Bryson, K. N. Reddy and I. C. Burke, "Morphological Comparison of Morningglory (Ipomoea and Jacquemontia spp.) Populations from the Southeastern
United States," Weed Science, Vol. 56, No. 5, 2008, pp. 692-698. doi:10.1614/WS-07-198.1

[14] C. D. Elmore, "Mode of Reproduction and Inheritance of Leaf Shape in Ipomoea hederacea," Weed Science, Vol. 34, 1986, pp. 391-395.

[15] M. Jasieniuk and B. D. Maxwell, "Plant Diversity: New Insights from Molecular Biology and Genomics Technologies," Weed Science, Vol. 49, No. 2, 2001, pp. 257-265.

doi:10.1614/0043-1745(2001)049[0257:PDNIFM]2.0.CO;2

[16] L. Dekker, "Weed Diversity and Weed Management," Weed Science, Vol. 45, 1997, pp. 357-363.

[17] E. P. Odum, "Fundamentals in Ecology," 3rd Edition, W. B. Saunders Co., Philadelphia, 1971.

[18] I. C. Burke, K. N. Reddy and C. T. Bryson, "Pitted and Hybrid Morningglory Accessions Have Variable Tolerance to Glyphosate," Weed Technology, Vol. 23, No. 4, 2009, pp. 592-598. doi:10.1614/WT-09-028.1

[19] J. J. Doyle and J. L. Doyle, "Isolation of Plant DNA from Fresh Tissue," Focus, Vol. 1, 1990, pp. 13-15.

[20] J. C. Huang and M. Sun, "Genetic Diversity and Relationships of Sweet Potato and Its Wild Relatives in Ipomoea series Batatas (Convolvulaceae) as Revealed by Inter-Simple Sequence Repeat (ISSR) and Restriction Analysis of Chloroplast DNA," Theoretical and Applied Genetics, Vol. 100, No. 7, 2000, pp. 1050-1060. doi: $10.1007 / \mathrm{s} 001220051386$

[21] M. V. Katti, P. K. Ranjekar and V. S. Gupta, "Differential Distribution of Simple Sequence Repeats in Eukaryotic Genome Sequences," Molecular Biology and Evolution, Vol. 18, 2001, pp. 1161-1167.

[22] E. Zietkiewicz, A. Rafalski and D. Labuda, "Genomic Fingerprinting by Simple Sequence Repeat (SSR)-Anchored Polymerase Chain Reaction Amplification," Genomics, Vol. 20, 1994, pp. 176-183.

[23] B. Liu and J. F. Wendel, "Intersimple Sequence Repeat (ISSR) Polymorphisms as a Genetic Marker in Cotton," Molecular Ecology Notes, Vol. 1, No. 3, 2001, pp. 205-208. doi:10.1046/j.1471-8278.2001.00073.x

[24] M. Morgante and M. Olivieri, "PCR-Amplified Microsatellites as Markers in Plant Genetics," Plant Journal, Vol. 3, 1993, pp. 175-182. doi:10.1111/j.1365-313X.1993.tb00020.x

[25] P. C. O. Hanlon, R. Peakall and D. T. Briese, "A Review of New PCR-Based Genetic Markers and Their Utility to Weed Ecology," Weed Research, Vol. 40, No. 3, 2000, pp. 239-254. doi:10.1046/j.1365-3180.2000.00191.x

[26] M. Z. Galvan, B. Bornet, P. A. Balatti and M. Branchard, "Inter Simple Sequence Repeat (ISSR) Markers as a Tool for the Assessment of Both Genetic Diversity and Gene Pool Origin in Common Bean (Phaseolus vulgaris L.)," Euphytica, Vol. 123, 2003, pp. 297-301.

[27] G. A. Lallemand and M. Bourgoin, "Fast and Reliable Strawberry Cultivar Identification Using Inter Simple Sequence Repeat (ISSR) Amplification," Euphytica, Vol. 129, 2002, pp. 69-79. 
[28] B. J. Parsons, H. J. Newbury, M. T. Jackson and B. V. Ford-Lloyd, "Contrasting Genetic Diversity Relationships Are Revealed in Rice (Oryza sativa L.) Using Different Marker Types," Molecular Breeding, Vol. 3, No. 2, 1997, pp. 115-125. doi:10.1023/A:1009635721319

[29] M. Nei, "Genetic Distance between Populations," American Naturalist, Vol. 106, 1972, pp. 283-292.

[30] K. Liu and S. V. Muse, "PowerMarker: An Integrated Analysis Environment for Genetic Marker Analysis," Bioinformatics, Vol. 21, 2005, pp. 2128-2129.

[31] F. J. Rohl, "NTSYS-pc: Numerical Taxonomy System, v 2.21," Exeter Publishing, Ltd., New York, 2008.

[32] G. McVean, "A Genealogical Interpretation of Principal Components Analysis," PLoS Genetics, Vol. 5, No. 10, 2009, p. e1000686. doi:10.1371/journal.pgen.1000686

[33] J. K. Pritchard, M. Stephens and P. Donnelly, "Inference of Population Structure Using Multilocus Genotype Data," Genetics, Vol. 155, 2000, 945-959.

[34] D. Falush, M. Stephens and J. K. Pritchard, "Inference of Population Structure Using Multilocus Genotype Data: Linked Loci and Correlated Allele Frequencies," Genetics, Vol. 164, 2003, pp. 1567-1587.

[35] A. L. Price, N. J. Patterson, R. M. Plenge, M. E. Weinblatt, N. A. Shadick and D. Reich, "Principal Components Analysis Corrects for Stratification in Genome-Wide Association Studies," Nature Genetics, Vol. 38, No. 8, 2006, pp. 904-909. doi:10.1038/ng1847

[36] N. Patterson, A. L. Price and D. Reich, "Population Structure and Eigen Analysis," PloS Genetics, Vol. 2, No. 12, 2006, p. e190. doi:10.1371/journal.pgen.0020190

[37] H. A. Agrama and G. C. Eizenga, "Molecular Diversity and Genome-Wide Linkage Disequilibrium Pattern in Worldwide Rice and Its Wild Relatives," Euphytica, Vol. 160, 2008, pp. 339-355.

[38] H. A. Agrama, J. M. Yan, R. Fjellstrom and A. M. McClung, "Genetic Structure Associated with Diversity and Geographic Distribution in the USDA Rice World Collection," Natural Science, Vol. 2, No. 4, 2010, pp. 247-291.doi:10.4236/ns.2010.24036

[39] G. C. Eizenga, H. A. Agrama, F. N. Lee and Y. Jia, "Exploring Genetic Diversity and Potential Novel Disease Resistance Genes in a Collection of Rice Wild Relatives," Genetic Resources and Crop Evolution, Vol. 56, No. 1, 2009, pp. 65-76. doi:10.1007/s10722-008-9345-7

[40] D. R. Gealy, H. A. Agrama and G. Eizenga, "Exploring the Genetic and Spatial Structure of U.S. Weedy Red
Rice (Oryza sativa) Accessions in Relation to Global Oryza spp.," Weed Science, Vol. 57, No. 6, 2009, pp. 627-643. doi:10.1614/WS-09-018.1

[41] V. K. Shivrain, N. R. Burgos, H. A. Agrama, A. Lawton-Rauh, B. LU, M. A. Sales, V. Boyett, D. R. Gealy and K. A. K. Moldenhauer, "Genetic Diversity of Weedy Rice (Oryza sativa L.) in Arkansas, USA," Weed Research, Vol. 50, 2010, pp. 289-302.

[42] J. Xie, H. A. Agrama, D. Kong, J. Zhuang, W. Yan, B. $\mathrm{Hu}$ and $\mathrm{Z}$. Zhuang, "Genetic Diversity of Endangered Dongxiang Wild Rice (Oryza rufipogon)," Genetic Resources and Crop Evolution, Vol. 57, No. 4, 2010, pp. 597-609. doi:10.1007/s10722-009-9498-Z

[43] W. Yan, H. A. Agrama, M. Jia, R. Fjellstrom and A. M. McClung, "Geographic Description of Genetic Diversity and Genetic Relationships in the USDA Rice World Collection," Crop Science, Vol. 50, No. 6, 2010, pp. 2406-2417. doi:10.2135/cropsci2010.02.0096

[44] G. Evanno, S. Regnaut and J. Goudet, "Detecting the Number of Clusters of Individuals Using the Software STRUCTURE: A Simulation Study," Molecular Ecology, Vol. 14, No. 8, 2005, pp. 2611-2620. doi:10.1111/j.1365-294X.2005.02553.x

[45] L. Excoffer, G. Laval and S. Schneider, "Arlequin (Version 3.0): An Integrated Software Package for Population Genetics Data Analysis," Evolutionary Bioinformatics Online, Vol. 1, 2005, pp. 47-50.

[46] S. A. Senseman and L. R. Oliver, "Flowering Patterns, Seed Production, and Somatic Polymorphism of Three Weed Species," Weed Science, Vol. 41, 1993, pp. 418425.

[47] B. Tanyolac, "Inter-Simple Sequence Repeat (ISSR) and RAPD Variation Among Wild Barley Hordeum vulgare subsp. spontaneum) Populations from West Turkey," Genetic Resources in Crop Evolution, Vol. 50, No. 6, 2003, pp. 611-614. doi:10.1023/A:1024412814757

[48] S. P. Joshi, V. S. Gupta, R. K. Aggarwal, P. K. Ranjekar and D. S. Brar, "Genetic Diversity and Phylogenetic Relationship as Revealed by Inter-Simple Sequence Repeat (ISSR) Polymorphism in the Genus Oryza," Theoretical and Applied Genetics, Vol. 100, No. 8, 2000, pp. 1311-1320._doi:10.1007/s001220051440

[49] T. Nagaoka and Y. Ogihara, "Applicability of Inter-Simple Sequence Repeat Polymorphisms in Wheat for Use as DNA Markers in Comparison to RFLP and RAPD Markers," Theoretical and Applied Genetics, Vol. 94, No. 5, 1997, pp. 597-602. doi:10.1007/s001220050456 